Transportation and Traffic Theory 2009:

Golden Jubilee 
William H. K. Lam · S. C. Wong · Hong K. Lo Editors

\section{Transportation and Traffic Theory 2009: Golden Jubilee}

Papers selected for presentation at ISTTT18, a peer reviewed series since 1959

旬 Springer 


\title{
Editors
}

William H.K. Lam

Department of Civil and Structural Engineering

The Hong Kong Polytechnic University

Hung Hom, Kowloon

Hong Kong SAR

cehklam@polyu.edu.hk

Hong K. Lo

Department of Civil and

Environmental Engineering

The Hong Kong University of Science

and Technology

Clear Water Bay, Kowloon

Hong Kong SAR

cehklo@ust.hk

\author{
S.C. Wong \\ Department of Civil Engineering \\ The University of Hong Kong \\ Hong Kong SAR \\ hhecwsc@hkucc.hku.hk
}

\author{
ISBN 978-1-4419-0819-3 \\ e-ISBN 978-1-4419-0820-9 \\ DOI 10.1007/978-1-4419-0820-9 \\ Springer Dordrecht Heidelberg London New York
}

Library of Congress Control Number: 2009930423

(C) Springer Science+Business Media, LLC 2009

All rights reserved. This work may not be translated or copied in whole or in part without the written permission of the publisher (Springer Science+Business Media, LLC, 233 Spring Street, New York, NY 10013, USA), except for brief excerpts in connection with reviews or scholarly analysis. Use in connection with any form of information storage and retrieval, electronic adaptation, computer software, or by similar or dissimilar methodology now known or hereafter developed is forbidden.

The use in this publication of trade names, trademarks, service marks, and similar terms, even if they are not identified as such, is not to be taken as an expression of opinion as to whether or not they are subject to proprietary rights.

Printed on acid-free paper

Springer is part of Springer Science+Business Media (www.springer.com) 


\section{Contents}

$\begin{array}{ll}\text { Preface } & \text { ix }\end{array}$

Remembering Ryuichi Kitamura xii

Organizers and Local Organizing Committee xiv

Funding and Supporting Organizations $\quad$ XV

International Advisory Committee, Founders and Honorary xvi

Members

Contributors $\quad$ xix

1 A Game Theoretic Approach to the Determination of Hyperpaths in 1 Transportation Networks

Jan-Dirk Schmöcker, Michael G.H. Bell, Fumitaka Kurauchi,

Hiroshi Shimamoto

2 Network Equilibrium under Cumulative Prospect Theory and

Endogenous Stochastic Demand and Supply

Agachai Sumalee, Richard D. Connors, Paramet Luathep

3 Estimation of Parameters of Network Equilibrium Models: A

Maximum Likelihood Method and Statistical Properties of Network

Flow

Shoichiro Nakayama, Richard D. Connors, David Watling

4 Spatiotemporal Effects of Segregating Different Vehicle Classes on

Separate Lanes

Michael J. Cassidy, Carlos F. Daganzo, Kitae Jang, Koohong

Chung

$5 \quad$ Microscopic Traffic Behaviour near Incidents

Victor L. Knoop, Henk J. van Zuylen, Serge P. Hoogendoorn

6 Understanding Stop-and-go Traffic in View of Asymmetric Traffic Theory

Hwasoo Yeo, Alexander Skabardonis

7 A Stochastic $\alpha$-Reliable Mean-Excess Traffic Equilibrium Model with Probabilistic Travel Times and Perception Errors

Anthony Chen, Zhong Zhou 
8 Equilibrium Trip Scheduling in Congested Traffic under Uncertainty

Barbara W.Y. Siu, Hong K. Lo

9 Reliable a Priori Shortest Path Problem with Limited Spatial and Temporal Dependencies

Yu (Marco) Nie, Xing Wu

10 Risk Averse Second Best Toll Pricing

Xuegang (Jeff) Ban, Shu Lu, Michael Ferris, Henry X. Liu

11 Cordon Pricing Consistent with the Physics of Overcrowding

Nikolas Geroliminis, David M. Levinson

12 Build-operate-transfer Schemes for Road Franchising with Road Deterioration and Maintenance Effects

Zhijia Tan, Hai Yang, Xiaolei Guo

13 Equilibria and Inefficiency in Traffic Networks with Stochastic Capacity and Information Provision

Tian-Liang Liu, Hai-Jun Huang, Hai Yang, Xiaolei Guo

14 An Active-set Algorithm for Discrete Network Design Problems

Lihui Zhang, Siriphong Lawphongpanich, Yafeng Yin

15 Multi-class Multi-modal Network Equilibrium with Regular Choice 301 Behaviors: a General Fixed Point Approach Meng Xu, Ziyou Gao

16 Existence of Equilibrium in a Continuous Dynamic Queueing Model for Traffic Networks with Responsive Signal Control Richard Mounce

17 Harmonic Analysis and Optimization of Traffic Signal Systems Nathan H. Gartner, Rahul Deshpande

18 A Two-direction Method of Solving Variable Demand Equilibrium 365 Models with and without Signal Control Mike Smith

19 Modeling Learning Impacts on Day-to-Day Travel Choice Ozlem Yanmaz-Tuzel, Kaan Ozbay 
20 A Probit-based Joint Discrete-continuous Model System: Analyzing 403 the Relationship between Timing and Duration of Maintenance Activities

Xin Ye, Ram M. Pendyala

21 Bayesian Learning, Day-to-Day Adjustment Process, and Stability of Wardrop Equilibrium

Shoichiro Nakayama

22 Hotspot Identification: A Full Bayesian Hierarchical Modeling Approach

H.L. Huang, H.C. Chin, M.M. Haque

23 The Continuous Risk Profile Approach for the Identification of High

Collision Concentration Locations on Congested Highways

Koohong Chung, David R. Ragland, Samer Madanat, Soon Mi Oh

24 Driver Behavior, Dilemma Zone, and Capacity at Red Light Camera Equipped Intersections Yohannes Weldegiorgis, Manoj K. Jha

25 Optimization of a Bus and Rail Transit System with Feeder Bus Services under Different Market Regimes Zhi-Chun Li, William H.K. Lam, S.C. Wong

26 Modelling Dynamic Generation of a Choice Set in Pedestrian Networks

Takamasa Iryo, Yasuo Asakura, Ryota Onishi, Chiharu Samma

27 A Common Modeling Framework for Dynamic Traffic Assignment and Supply Chain Management Systems with Congestion Phenomena Georgios Kalafatas, Srinivas Peeta

28 A Pedestrian Model Considering Anticipatory Behaviour for Capacity Evaluation Miho Asano, Takamasa Iryo, Masao Kuwahara

29 A Comparative Assessment of Stochastic Capacity Estimation Methods Justin Geistefeldt, Werner Brilon 
30 Supply-demand Diagrams and a New Framework for Analyzing the 603 Inhomogeneous Lighthill-Whitham-Richards Model

W.L. Jin, L. Chen, Elbridge Gerry Puckett

31 Network Evaluation Based on Connectivity Vulnerability

Fumitaka Kurauchi, Nobuhiro Uno, Agachai Sumalee, Yumiko Seto

32 Reliability-based Dynamic Discrete Network Design with

Stochastic Networks

Hao Li, Michael C.J. Bliemer, Piet H.L. Bovy

33 Flow Breakdown, Travel Reliability and Real-time Information in

Route Choice Behavior

Jing Dong, Hani S. Mahmassani

34 Optimal Sensor Placement for Freeway Travel Time Estimation Xuegang (Jeff) Ban, Ryan Herring, J.D. Margulici, Alexandre M.

Bayen

35 Updating Dynamic Origin-destination Matrices using Observed Link Travel Speed by Probe Vehicles

Toshiyuki Yamamoto, Tomio Miwa, Tomonori Takeshita, Takayuki Morikawa

Previous Symposia and Proceedings 


\section{Preface}

It is our great privilege and honor to present the proceedings of the $18^{\text {th }}$ International Symposium on Transportation and Traffic Theory (ISTTT), held at The Hong Kong Polytechnic University in Hong Kong, China on 16-18 July 2009. The $18^{\text {th }}$ ISTTT is jointly organized by the Hong Kong Society for Transportation Studies and Department of Civil and Structural Engineering of The Hong Kong Polytechnic University.

The ISTTT series is the main gathering for the world's transportation and traffic theorists, and those who are interested in contributing to or gaining a deep understanding of traffic and transportation phenomena in order to better plan, design and manage the transportation system. Although it embraces a wide range of topics, from traffic flow theories and demand modeling to road safety and logistics and supply chain modeling, the ISTTT is hallmarked by its intellectual innovation, research and development excellence in the treatment of real-world transportation and traffic problems. The ISTTT prides itself in the extremely high quality of its proceedings. Previous ISTTT conferences were held in Warren, Michigan (1959), London (1963), New York (1965), Karlsruhe (1968), Berkeley, California (1971), Sydney (1974), Kyoto (1977), Toronto (1981), Delft (1984), Cambridge, Massachusetts (1987), Yokohama (1990), Berkeley, California (1993), Lyon (1996), Jerusalem (1999), Adelaide (2002), College Park, Maryland (2005), and London (2007).

This $18^{\text {th }}$ ISTTT celebrates the $50^{\text {th }}$ Anniversary of this premier conference series. The first Symposium, organized by Professor Robert Herman, was held on 7-8 December 1959. A total of 15 papers were presented in the $1^{\text {st }}$ Symposium. The scope of this Symposium series has since broadened, from the Symposium on the Theory of Traffic Flow to the International Symposium on Transportation and Traffic Theory. The ISTTT has also grown in size, but is still limited to around 35 papers. The rationale is, as was since the $1^{\text {st }}$ Symposium, to allow ample time for presentation and informal discussion. Indeed, this time, in celebrating the $50^{\text {th }}$ Anniversary of this tradition, we have arranged roundtable discussions to further enhance the interactions among researchers, scientists, and practitioners. We hope to have an opportunity to reminisce advances made in the past, and to outline important, uncharted territories. In reviewing the outline of the $1^{\text {st }}$ Symposium, we were awed by the foresights of the researchers then, addressing research topics such as traffic control, distribution of traffic on a network and that of households and workplaces, clustering tendency of vehicular traffic, modeling traffic via stochastic processes, and simulation of bottlenecks, etc. These topics appear as fresh today as they were posed 50 years ago, despite much progress having been made. Transportation and traffic theories renew themselves as technology advances, as human activities are re-organized, and as scarce resources become gradually depleted, etc, representing our best effort at the time to understand and 
hence manage the needs and consequences of connecting activities, goods, and people. From this vantage point, we are confident that the best years for ISTTT are yet to come in the future.

It is timely to organize the $18^{\text {th }}$ ISTTT in Hong Kong, as the thrust of transportation infrastructure development has emerged strongly in Asia. Indeed, many parts of Asia are currently undertaking extensive transportation infrastructure programs. Hong Kong, for example, will initiate 10 major infrastructure projects with an investment of about HK\$250 billion (roughly US\$32 billion), in which 6 are transportation projects, including 4 railway and 2 highway infrastructure projects. These transportation infrastructures will bring about an economic benefit of more than HK $\$ 100$ billion (roughly US\$12 billion) annually, amounting to some $7 \%$ of the GDP of Hong Kong in 2006. This points to the imminent demand of high caliber transportation and traffic planners and engineers for the planning, design, management and operation of the transportation systems. The $18^{\text {th }}$ ISTTT offers an excellent platform to elevate the role of transportation and traffic theories for transportation infrastructure planning and operations.

Special thanks are given to Members of the International Advisory Committee (IAC) and the local organizing committee for reviewing the extended abstracts and then full paper submissions, especially under the short review time requested of them. Our particular appreciation is extended to the referees who have contributed their considerable time and effort to the two-tier review process. With their dedicated support, each paper submission received at least three reviews, typically four to five, sometimes up to six reviews. Given the extremely high selectivity, we have tried our very best to ensure that each paper submission received a sufficient number of reviews to evaluate its merit. In reality, the tight constraint on the number of papers to be accepted for this Symposium have forced us to decline a number of very high quality submissions, which would be acceptable for publications in quality transportation journals. All in all, out of 230 extended abstract submissions, we have finally selected 35 papers to be included in this volume. We sincerely hope that this volume will serve as a vehicle to stimulate novel research initiatives in transportation and traffic theories.

As this volume was heading towards press, the news of Ryuichi Kitamura's untimely death on 19 February 2009 struck us with sadness and a profound sense of loss. A professor at Kyoto University, Ryuichi had given his unstinting support to ISTTT as a Member of the IAC. All of us who had the good fortune of having met him were often touched by his cheerfulness, kindness, and generosity. His positive attitude and warmth endured even when he was suffering from a long illness. We shall sorely miss his scholarship and friendship.

This commemorative Symposium volume is dedicated to researchers, scientists, and practitioners who have spent their career advancing the state-of-the-art in 
transportation and traffic theories. We celebrate their accomplishments and honor the memory of those who are not with us today.

Finally, we express our gratitude to the organizations whose financial contribution has made it possible for us to host the $18^{\text {th }}$ ISTTT in Hong Kong.

William H. K. Lam, S.C. Wong and Hong K. Lo

March 2009 


\section{Remembering Ryuichi Kitamura}

On February 19, 2009, many of us were saddened to hear of Ryuichi Kitamura's passing. His close friends and colleagues had known for some time of his struggle with cancer, but had drawn hope from his appearances at conferences and occasional correspondence. He taught us a lot about how to be graceful in the face of adversity, as he remained his wonderful positive self until the end, and continued to write and conduct far-reaching research with his students and collaborators. He had hoped to attend the $18^{\text {th }}$ ISTTT meeting in Hong Kong, but unfortunately it was not meant to be.

Ryuichi returned to Kyoto University, his alma mater, in 1993, as a Professor of Urban Management in the Faculty of Engineering, after a distinguished 15-year career on the faculty of the Department of Civil and Environmental Engineering at the University of California at Davis, where he was instrumental in founding the Institute for Transportation Studies (ITS). He received his BS in Civil Engineering and MS in Transportation in 1972 and 1974, respectively, from Kyoto University, and $\mathrm{ahD}$ in Civil Engineering from the University of Michigan at Ann Arbor in 1978 .

Through his research, teaching and professional service, Ryuichi played a key role in advancing the state of the art as well as state of practice in travel demand modeling and the dynamic analysis of transportation systems through microsimulation of household travel and activity behaviour. He realized early on that travel demand does not occur for its own sake, but is part of a broader set of activities undertaken by individuals and households in fulfilling their various needs. He became a major force in the US and internationally in promoting greater behavioural realism in transportation models, leading the way towards comprehensive activity-based models of travel demand.

Ryuichi challenged conventional wisdom and brought a fresh perspective to nearly all topics on which he worked. He was a scholar, with a probing inquisitive mind, who subtly but firmly made you look at problems from a different angle. He was a keen observer of social trends, and among the first to recognize how they might impact travel and transportation. Telecommuting, changing gender roles, increased environmental awareness and shifting preferences are examples of phenomena he sought to understand and quantify in terms of transportation implications. Ryuichi was one of few researchers who had the methodological firepower to analyze these kinds of trends rigorously, ranging from novel survey methods to advanced econometric and psychometric techniques.

His quest for models based on sound behavioural theories was promoted through several disciples who studied under him at both Davis and Kyoto, and who went on to become influential scholars and practitioners in their own right. He helped 
shape the field through his service as chair of the Traveller Behaviour and Values committee of the Transportation Research Board in the mid to late 1980's, a time of major advances in both research and practice. He served as President of the International Association of Travel Behaviour Research (IATBR) in 1992-94, and hosted its triennial meeting in Kyoto in 2006. In that same year, the IATBR recognized his contributions by awarding him the Lifetime Achievement Award.

Ryuichi was a member of the International Advisory Committee of the ISTTT, and had discussed with us his desire to host it in Kyoto at some future date. It is unfortunate he did not live to see this wish fulfilled. We will miss his thoughtful interventions and good humour, the depth of insight and breadth of perspective he brought to the ISTTT, and his warm, pleasant and congenial personality. I will miss a dear friend, who contributed so much to making what we do the exciting privilege it truly is.

Hani S. Mahmassani

March 2009 


\section{Organizers}

\section{Hong Kong Society for Transportation Studies}

and

\section{Department of Civil and Structural Engineering, The Hong Kong Polytechnic University}

\section{Local Organizing Committee}

William H.K. Lam

(Chairman)

S.C. Wong

(Co-Chairman)

Hong K. Lo

(Co-Chairman)

C.H. Cheng

Janny M.Y. Leung

Stephen C.H. Leung

H.P. Lo

Becky P.Y. Loo

Agachai Sumalee

C.O. Tong

Hai Yang
The Hong Kong Polytechnic University

The University of Hong Kong

The Hong Kong University of Science and Technology

The Chinese University of Hong Kong

The Chinese University of Hong Kong

City University of Hong Kong

City University of Hong Kong

The University of Hong Kong

The Hong Kong Polytechnic University

The University of Hong Kong

The Hong Kong University of Science and Technology 


\section{Funding Organizations}

Commerce and

Economic

Development Bureau, The Government of the Hong Kong Special Administrative Region

The Croucher Foundation

Faculty of Construction and Land Use, The Hong Kong Polytechnic University (FCLU)
The Professional Services Development Assistance Scheme (PSDAS) (http://www.cedb.gov.hk/citb/psdas) is established by a Government allocation of HK $\$ 100$ million to provide financial support for projects which aim at increasing the competitiveness of Hong Kong's professional service sector as a whole, or of individual sectors, in external markets including the Mainland market.

Disclaimer: Any opinions, findings, conclusions or recommendations expressed in this material / any event organized under this Project do not reflect the views of The Government of the Hong Kong Special Administrative Region or the Vetting Committee for the Professional Services Development Assistance Scheme.

Founded in 1979 by the late Mr. Noel Croucher, one of the founders of the original Hong Kong Stock Exchange and who contributed to the development of Hong Kong for nearly seven decades, with the object to promote the standard of natural sciences, technology and medicine through education and research activities in Hong Kong. http://www.croucher.org.hk/

FCLU (http://www.polyu.edu.hk/fclu/) is the biggest higher education provider of professional manpower for the Hong Kong construction industry. Virtually all aspects of construction from land surveying to transportation and infrastructure design, to actual construction and its management, to repair and refurbishment and to the operation and management of finished facilities are covered by the Faculty's programmes and its research activities.

\section{Supporting Organizations}

The Chartered Institute of Logistics and Transport in Hong Kong (CILTHK)

http://www.cilt.org.hk/

The Hong Kong Institution of Engineers, Civil Division

http://www.hkie.org.hk/ 


\title{
International Advisory Committee
}

\author{
Carlos F. Daganzo University of California, U.S.A. (Convenor) \\ Michael G.H. Bell Imperial College London, U.K. \\ Werner Brilon Ruhr-University Bochum, Germany \\ Avishai (Avi) Ceder Technion - Israel Institute of Technology, Israel \\ Nathan H. Gartner University of Massachusetts Lowell, U.S.A. \\ Ben G. Heydecker University College London, U.K. \\ Serge P. Hoogendoorn Delft University of Technology, The Netherlands \\ Ryuichi Kitamura Kyoto University, Japan \\ Reinhart Kühne German Aerospace Center, Germany \\ Masao Kuwahara University of Tokyo, Japan \\ William H.K. Lam The Hong Kong Polytechnic University, Hong Kong \\ Jean-Baptiste Lesort Institut National de Recherche sur les Transports et \\ leur Sécurité, France \\ Hani S. Mahmassani Northwestern University, U.S.A. \\ Valentin Silyanov Moscow Automobile and Roads Institute (State \\ Technical University), Russia \\ Michael Taylor University of South Australia, Australia \\ Marian Tracz Cracow University of Technology, Poland \\ S.C. Wirasinghe University of Calgary, Canada
}




\section{Founders}

Martin Beckmann

Leslie Edie

Denos Gazis

Robert Herman

Wilhelm Leutzbach

Alan Miller

Gordon Newell

Renfrey Potts

Ilya Prigogine

Richard Rothery

Tsuna Sasaki

Reuben Smeed

John Tanner

John Wardrop

\section{Honorary Members}

$\begin{array}{lll}\text { Richard Allsop } & \text { U.K. } & \text { Convenor 1981-1996 } \\ \text { Ezra Hauer } & \text { Canada } & \text { Convenor 1996-2002 } \\ \text { Piet H.L. Bovy } & \text { The Netherlands } & \\ \text { Hartmut Keller } & \text { Germany } & \\ \text { Masaki Koshi } & \text { Japan } & \text { Germany } \\ \text { Wilhelm Leutzbach } & \text { Japan } & \\ \text { Yasuji Makigami } & \text { Germany } & \\ \text { Hans-Georg Retzko } & \text { U.K. } \\ \text { Dennis Robertson } & \text { Canada }\end{array}$




\section{Contributors}

\begin{tabular}{|c|c|}
\hline Yasuo Asakura & $\begin{array}{l}\text { Kobe University } \\
\text { Japan }\end{array}$ \\
\hline Miho Asano & $\begin{array}{l}\text { National Institute for Land and Infrastructure } \\
\text { Management, Japan }\end{array}$ \\
\hline Xuegang (Jeff) Ban & $\begin{array}{l}\text { Rensselaer Polytechnic Institute } \\
\text { U.S.A. }\end{array}$ \\
\hline Alexandre M. Bayen & $\begin{array}{l}\text { University of California } \\
\text { U.S.A. }\end{array}$ \\
\hline Michael G.H. Bell & $\begin{array}{l}\text { Imperial College London } \\
\text { U.K. }\end{array}$ \\
\hline Michael C.J. Bliemer & $\begin{array}{l}\text { Delft University of Technology } \\
\text { The Netherlands }\end{array}$ \\
\hline Piet H.L. Bovy & $\begin{array}{l}\text { Delft University of Technology } \\
\text { The Netherlands }\end{array}$ \\
\hline Werner Brilon & $\begin{array}{l}\text { Ruhr-University Bochum } \\
\text { Germany }\end{array}$ \\
\hline Michael J. Cassidy & $\begin{array}{l}\text { University of California } \\
\text { U.S.A. }\end{array}$ \\
\hline Anthony Chen & $\begin{array}{l}\text { Utah State University } \\
\text { U.S.A. }\end{array}$ \\
\hline L. Chen & $\begin{array}{l}\text { University of Science and Technology of China } \\
\text { China }\end{array}$ \\
\hline H.C. Chin & $\begin{array}{l}\text { National University of Singapore } \\
\text { Singapore }\end{array}$ \\
\hline Koohong Chung & $\begin{array}{l}\text { California Department of Transportation } \\
\text { U.S.A. }\end{array}$ \\
\hline Richard D. Connors & $\begin{array}{l}\text { University of Leeds } \\
\text { U.K. }\end{array}$ \\
\hline Carlos F. Daganzo & $\begin{array}{l}\text { University of California } \\
\text { U.S.A. }\end{array}$ \\
\hline Rahul Deshpande & $\begin{array}{l}\text { University of Massachusetts Lowell } \\
\text { U.S.A. }\end{array}$ \\
\hline Jing Dong & $\begin{array}{l}\text { Northwestern University } \\
\text { U.S.A. }\end{array}$ \\
\hline Michael Ferris & $\begin{array}{l}\text { University of Wisconsin-Madison } \\
\text { U.S.A. }\end{array}$ \\
\hline Ziyou Gao & $\begin{array}{l}\text { Beijing Jiaotong University } \\
\text { China }\end{array}$ \\
\hline Nathan H. Gartner & $\begin{array}{l}\text { University of Massachusetts Lowell } \\
\text { U.S.A. }\end{array}$ \\
\hline Justin Geistefeldt & $\begin{array}{l}\text { Hessian Road and Traffic Authority } \\
\text { Germany }\end{array}$ \\
\hline Nikolas Geroliminis & $\begin{array}{l}\text { University of Minnesota } \\
\text { U.S.A. }\end{array}$ \\
\hline
\end{tabular}


Xiaolei Guo

M.M. Haque

Ryan Herring

Serge P. Hoogendoorn

Hai-Jun Huang

H.L. Huang

Takamasa Iryo

Kitae Jang

Manoj K. Jha

W.L. Jin

Georgios Kalafatas

Victor L. Knoop

Fumitaka Kurauchi

Masao Kuwahara

William H.K. Lam

Siriphong Lawphongpanich

David M. Levinson

Hao Li

Zhi-Chun Li

Henry X. Liu

Tian-Liang Liu

Hong K. Lo
The Hong Kong University of Science and Technology, Hong Kong

National University of Singapore

\section{Singapore}

University of California

U.S.A.

Delft University of Technology

The Netherlands

Beijing University of Aeronautics and

Astronautics, China

University of Central Florida

U.S.A.

Kobe University

Japan

University of California

U.S.A.

Morgan State University

U.S.A.

University of California

U.S.A.

Purdue University

U.S.A.

Delft University of Technology

The Netherlands

Gifu University

Japan

The University of Tokyo

Japan

The Hong Kong Polytechnic University

Hong Kong

University of Florida

U.S.A.

University of Minnesota

U.S.A.

Delft University of Technology

The Netherlands

The Hong Kong Polytechnic University, Hong

Kong and Huazhong University of Science and

Technology, China

University of Minnesota

U.S.A.

Beijing University of Aeronautics and Astronautics, China

The Hong Kong University of Science and Technology, Hong Kong 
Shu Lu

Paramet Luathep

Samer Madanat

Hani S. Mahmassani

J.D. Margulici

Tomio Miwa

Takayuki Morikawa

Richard Mounce

Shoichiro Nakayama

$\mathrm{Yu}(\mathrm{Marco}) \mathrm{Nie}$

Soon Mi Oh

Ryota Onishi

Kaan Ozbay

Srinivas Peeta

Ram M. Pendyala

Elbridge Gerry Puckett

David R. Ragland

Chiharu Samma

Jan-Dirk Schmöcker

Yumiko Seto

Hiroshi Shimamoto

Barbara W.Y. Siu

Alexander Skabardonis
University of North Carolina at Chapel Hill

U.S.A.

The Hong Kong Polytechnic University

Hong Kong

University of California

U.S.A.

Northwestern University

U.S.A.

University of California

U.S.A.

Nagoya University

Japan

Nagoya University

Japan

Queen's University

U.K.

Kanazawa University, Japan and

University of Leeds, U.K.

Northwestern University

U.S.A.

University of California

U.S.A.

Hankyu Railway Company Limited

Japan

Rutgers University

U.S.A.

Purdue University

U.S.A.

Arizona State University

U.S.A.

University of California

U.S.A.

University of California

U.S.A.

JCB Company Limited

Japan

Tokyo Institute of Technology

Japan

Kyoto University

Japan

Hiroshima University

Japan

The Hong Kong University of Science and

Technology, Hong Kong

University of California

U.S.A. 
Mike Smith

Agachai Sumalee

Tomonori Takeshita

Zhijia Tan

Nobuhiro Uno

Henk J. van Zuylen

David Watling

Yohannes Weldegiorgis

S.C. Wong

Xing Wu

Meng Xu

Toshiyuki Yamamoto

Hai Yang

Ozlem Yanmaz-Tuzel

Xin Ye

Hwasoo Yeo

Yafeng Yin

Lihui Zhang

Zhong Zhou
University of York

U.K.

The Hong Kong Polytechnic University

Hong Kong

Shizuoka Prefecture

Japan

The Hong Kong University of Science and Technology, Hong Kong

Kyoto University

Japan

Delft University of Technology

The Netherlands

University of Leeds

U.K.

Morgan State University

U.S.A.

The University of Hong Kong

Hong Kong

Northwestern University

U.S.A.

Beijing Jiaotong University

China

Nagoya University

Japan

The Hong Kong University of Science and Technology, Hong Kong

Rutgers University

U.S.A.

University of Maryland

U.S.A.

University of California

U.S.A.

University of Florida

U.S.A.

University of Florida

U.S.A.

Citilabs

U.S.A. 